\title{
On grammatical relations as constraints on referent identification
}

\author{
Randy J. LaPolla \\ La Trobe University
}

\begin{abstract}
Based on a Relevance Theory-informed view of language development, this paper argues that grammatical relations are construction-specific conventionalizations (grammaticalizations) of implicatures which arise out of repeated patterns of reference to particular types of referents. Once conventionalized, these structures function to constrain the hearer's identification of referents in discourse. As they are construction-specific, and hence language-specific, there is no category "subject" across languages; different languages will either show this type of grammaticalization or not, and if they do, may show it or not in different constructions. Any cross-linguistic use of terms such as "subject" (and "S", as in "SOV") should then be avoided.
\end{abstract}

\section{Introduction ${ }^{\star}$}

In a 1991 paper, Prof. Shibatani discussed the grammaticalization of topic into subject. He argued for the following view of subjects in that paper (p. 103):

(a) it is a syntactic category resulting from the generalization of an agent over other semantic roles, (b) languages vary as to how far this generalization has taken place; i.e. the grammatical status of subject differs from one language to another, and therefore, (c) the subject is not necessarily a universal category.

Prof. Shibatani goes on to show how languages can differ in terms of the degree to which the reference-related properties of subject and the (semantic) rolerelated properties of subject are conflated on a single NP, and also in terms of which NP is grammaticalized into the subject. In this paper I would like to try to take the next step, to explain what it means for a language to grammaticalize phenomena we relate to the concept of "subject", and show the cognitive motivation for such a grammaticalization. I will also go a step further than 
Prof. Shibatani and argue that not only is "subject" not a universal category, it is not a category at all, but the lumping together of individual phenomena that function to constrain the interpretation of the nature of referents in discourse. In order to do that, though, I will need to first discuss the nature of communication and the role of language in communication.

\section{Ostension and inference}

Sperber and Wilson (1996; see also LaPolla 2003) argue that a coding-decoding model of communication cannot explain how communication is achieved between two people. Building on the blueprint model of Reddy (1979), they argue that what happens in communication is that one person makes some sort of ostensive act (a stimulus, an act obviously done for some purpose), and that, as a request for attention, this act directly communicates the intention of the person to communicate by means of that ostensive act, and at the same time is direct or indirect evidence of what the person intents to communicate. The ostensive act may be linguistic, but it may not be; it could be a simple movement of the hand, a raising of the eyebrow, or any other obviously purposely done action. Upon seeing or hearing the ostensive act, the addressee will first infer that the communicator intends to communicate some information using that ostensive act, and then will further attempt to infer the communicator's informative intention (the information that the communicator intends to communicate).

Underlying all of this is the assumption on the part of both communicator and addressee that both are rational people (and so act with goals in mind - see Grice 1975), and that the ostensive act automatically conveys a presumption of relevance, that is, that the information the communicator wishes to communicate is worth processing (i.e., it will improve the quality, quantity, and/or organization of the individual's knowledge), and that the effort to process it will not be unjustifiably great. Because the ostensive act communicates the presumption of its own relevance, the addressee will attempt to determine the reason why the communicator made that ostensive act by constructing a context of interpretation (a set of assumptions) in which the particular ostensive act the communicator produced will be relevant (i.e. will "make sense"), and thereby infer the informative intention of the communicator. Communication then relies on this one principle, the principle of relevance: the speaker assumes that the addressee will recognize the ostensive act as an attempt to communicate, and that the addressee will assume that the ostensive act is relevant in some way, and will then attempt to infer what that relevance is. 
Above I mentioned that there is also an assumption that the effort to process the ostensive act will not be unjustifiably great, and because of this, the addressee will also assume that the ostensive act is the most appropriate one that the speaker could use in that context with that addressee. Therefore, the addressee will choose the first accessible interpretation of the ostensive act (the reason for the speaker making the ostensive act) that seems relevant. The ostensive act may give direct evidence for what the communicator wishes to communicate (it may "show something"), such as when someone ostensibly rises out of a wheelchair and walks across the room to communicate that he can (now) walk, or it may give indirect evidence by saying something about it, such as if the same person just mentioned simply said I can walk. There is a continuum of cases between the two extremes of direct evidence and indirect evidence, and, more important for this paper, there is also a continuum of explicitness in terms of the indirect evidence given. The communicator will tailor the ostensive act in such a way that it will allow the interpreter to be able to infer the intended information, and without requiring the speaker or hearer to expend any unnecessary energy. The speaker then also must use inference, in this case infer what assumptions are manifest (known or could be known) to the hearer and which could be used in the context of interpretation. The greater the number of relevant assumptions available to the hearer, the less explicit the ostensive act need be. Consider the following example. My wife and I were rushing to clean up our living room, as guests were on their way over. She stretched out her arm and wagged her finger towards the far side of the room. I looked in that direction and noticed that my coat was on the couch, and I inferred that her communicative intention was for me to notice that the coat was on the couch and realize that it should not be on the couch, and so I should go get the coat and put it away. Rather than simply wagging her finger, she could have said any of the utterances given in (1):

(1) a. Your coat!

b. Get your coat!

c. Your coat is on the couch.

d. You should put your coat away.

e. Your coat is on the couch, and it shouldn't be there, so you had better go over and get it and put it away.

Because she just wagged her finger, I had to infer that I should look in the direction she was wagging towards, then had to try to infer that it was the coat she was wagging her finger at, and then infer that the coat being on the couch was significant, and then infer what the significance of it being there was, and then 
infer that she intended for me to do something about the coat being on the couch. I was able to do all of that inferential work successfully because of certain contextual assumptions that I could add to the context of interpretation, such as the semantic frame of "cleaning up", and the assumption that whatever was communicated within that frame would be relevant to that frame. If these assumptions were not manifest to me, such as if I had been sitting working on my computer and she wagged her finger the same way, I would not be able to understand her intention with such a simple ostensive act. She would have to use one of the more explicit ostensive acts given in (1). She could use (1a) if she thought I would have trouble trying to infer what referent she intended me to notice. She could use (1b) if she thought I would have trouble inferring that she wanted me to get the coat. She could use (1c) if she thought I would have trouble inferring that the coat being on the couch was somehow significant. She could use (1d) if she thought I would have trouble inferring what I should do with the coat. And she could use (1e) if she wanted to be sure I would have little trouble inferring all aspects of her intention. Greater explicitness can be achieved through the addition of more lexical items, the addition of grammatical marking, or, more commonly, through the addition of both. Here grammatical marking includes both grammatical forms, such as the genitive marking and the word so in (1e), and also grammatical constructions that constrain the interpretation of some aspect of the speaker's intention, such as the constructions we will be talking about here (relevant to grammatical relations) for constraining the identification of referents.

Languages differ in terms of what functional domains the speakers must obligatorily constrain. Obligatory marking develops when speakers constrain the interpretation in a particular way so often that it becomes conventionalized and thereby recognized as unmarked. Failure to use the marking will not necessarily lead to misinterpretation, but will be seen as marked, "wrong", or "ungrammatical". In the case of (1d), Should put coat away would not be an acceptable utterance, as English conventions require the speaker to overtly mention a Subject and to overtly constrain the identification of the coat with a genitive or demonstrative pronoun. This is not true of all languages. Languages also differ in the degree to which the interpretation of a particular functional domain is constrained. Two languages may, for example, both obligatorily constrain the interpretation of the time of an action relative to the speech act time (i.e. have grammaticalized tense marking), but one language may only distinguish one past tense, while the other language distinguishes four past tenses (e.g. English and Rawang, a Tibeto-Burman language of northern Burma, respectively). Languages that constrain the interpretation of a particular functional 
domain may also differ in terms of the particular formal mechanism used to constrain the interpretation. (See LaPolla 2003 for examples and discussion.)

\section{Grammatical relations}

In this paper we are interested in conventionalized patterns and marking which are related to grammatical relations and their function in constraining the creation of the context of interpretation. For example, in English, an NP that immediately precedes a verb will be understood to be representing the actor of the action represented by the verb, if the verb is an action-type verb and is in the active voice, and the NP will be seen as representing the patient or recipient of the action represented by the verb if the verb is in the passive voice. ${ }^{1}$ A noun phrase that immediately follows a verb will be understood as representing the patient, benefactive, or recipient of the action represented by the verb. That is, word order in the clause is obligatorily used to constrain the interpretation of who is doing what to whom. In example (1d), we were forced to assume that you was representing the actor and your coat was representing the patient because of their positions relative to the verb, and this information was added to our context of interpretation. The NP in preverbal position has to be the A (agentive argument) of a transitive verb or the $\mathrm{S}$ (single direct argument) of an intransitive verb when the verb is in the active voice. This restricted neutralization of roles in that position gives that particular NP a special status we will call "pivot". ${ }^{2}$ Not all languages use word order to constrain the identification of referents. For example, word order in Chinese does not constrain the interpretation of the role of the referent of an NP; the hearer must rely on real-world knowledge and expectations to infer whether an NP is representing an actor or something else. Consider the following examples: ${ }^{3}$

(2) a. Xúeshēng fâ-le chéngjūiān. student distribute-AsP grade.report 'The students were given their grade reports.'

b. Lăoshì fā-le chéngjìdān.

teacher distribute-AsP grade.report

'The teacher distributed the grade reports.'

The interpretation of the initial NP of both clauses could be either that it represents an actor, or it represents a recipient, but in most cases assumptions from real-world knowledge, such the fact that usually teachers distribute grade reports and usually students receive them, would be added to the context of 
interpretation, and so the meanings would most likely those given in the free translations. The important point here is that the position of the NP does not constrain the identification of the referent of the NP as actor or recipient the way it does in English.

There are several other constructions in English that also work in a similar way, that is, constrain the identification and roles of the referents mentioned, and the majority of these all identify an $[\mathrm{A}, \mathrm{S}]$ pivot. This pivot is what has come to be known as "subject" in English. It isn't the case that all constructions and marking that constrain the identification of referents are related to what we think of as "subject" (e.g. gender systems, possessor marking), but I would like to argue that all of the phenomena we lump together as "subject" phenomena are involved in referent identification, and they develop as speakers consistently use a particular pattern of coreference or word order often enough that it becomes conventionalized (grammaticalized), and so then obligatorily forces a particular interpretation.

Let us look now at other constructions and marking which are seen as "subject" phenomena to see how they constrain the identification of referents. In (3) we have a conjoined structure.

(3) John hit Bill and cried.

In this example, even if we have no contextual information, we must assume that the referent of the initial noun phrase, John, is the one who cried (cf. Comrie 1988). This is because the speakers of English have conventionalized a cross-clause coreference pattern in conjoined clauses where the second clause does not have an overt referent mentioned in the clause. The pivot of this construction is also $[\mathrm{A}, \mathrm{S}]$, that is, the zero pronoun in the second clause must be coreferential with an A or S in the first clause. This is not true of all languages. There are two possibilities, either a different pivot might be identified, or the language may not have any pivot for this construction. Dyirbal (Dixon 1972, 1980 ) is a famous example of a language that has grammaticalized a different pivot in this construction; the pivot is a $[\mathrm{P}, \mathrm{S}]$ pivot, not an $[\mathrm{A}, \mathrm{S}]$ pivot. That is, the construction applies to a patient $(\mathrm{P})$ and the single argument of an intransitive verb (S), but not to an Actor (A). Consider the example in (4) (from Dixon 1980:462).

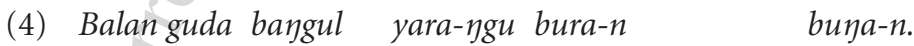
she+ABs dog+ABs he+ERg man-erg see-PASt descend-PAST 'The man saw the dog and (the dog) went downhill.' 
This example has a similar structure to the English example in (3), but the interpretation of the zero pronoun in the second clause is obligatorily coreferential with the $\mathrm{P}$ in the first clause, that is, it must be that the dog is the one that went downhill.

An example of a language that has not grammaticalized a pivot for this construction is Rawang, a Tibeto-Burman language of northern Burma:

(5) a. Vpūngí Vdǿsìng vdip bǿà nø̀ ngǿa:pmì

Vpūng-í Vdó-sìng vdip bó-à . nò

ypung-AGT Adeu-LOC hit PFV-Trans.PAST PS

ngó-ap-ì

cry-TMdys-Intrans.PAST

'Apung hit Adeu and cried.' (Adeu cried)

b. Vpūngí Vdǿsìng vdip bǿà nø̀ vhø̄shì a:pmì

Vpūng-í Vdó-sìng vdip bó-à nò vhō-shì

Apung-AGT Adeu-LOC hit PFV-Trans.PAST Ps laugh-R/M

$a p-\grave{\imath}$

TMdys-Intrans.PAST

'Apung hit Adeu and laughed.' (Apung laughed)

Here the structures in (5a) and (5b) are exactly the same, though the actor of the second clause is interpreted differently due to real world expectations of who would be more likely to cry or laugh after an act of hitting. There is no grammatical constraint on the interpretation of the referent of the zero in the second clause. I've written 'Adeu cried' and 'Apung laughed' after the free translations, but the interpretation could be that the one who cried or laughed was either one of these two people, or even a third person, such as someone standing nearby watching what was happening between Adeu and Apung. Most Sino-Tibetan languages are similar to Rawang and Chinese (LaPolla 1993) in not having syntactic constraints that force particular interpretations of crossclause coreference.

What is important here is how a conventionalized pattern of coreference constrains the hearer's creation of the context of interpretation. In English, the hearer cannot create a context of interpretation that includes an assumption that would lead to the $\mathrm{P}$ argument being seen as coreferential with the zero of the second clause, for example, in terms of (3), that someone who gets hit is more likely to cry (and so the interpretation of (3) might be that Bill cried). In Dyirbal the hearer cannot create a context of interpretation that includes an assumption that would lead to the A argument being seen as coreferential with the zero of the second clause, for example, in terms of (4), some real- 
world consideration that might lead to the interpretation that the man went downhill. In Rawang there isn't any conventionalized coreference pattern, and so the hearer is not constrained in the creation of the context of interpretation. The structures conventionalized ${ }^{4}$ in English and Dyirbal force particular interpretations (or at least limit the possible interpretations), while in Rawang the interpretation remains unconstrained.

In English, verb agreement is another aspect of the grammar associated with subject that constrains the identification of the relevant referent to an A or S. The number marking in the agreement paradigm also helps constrain the identification of the referent. In (6) the use of singular vs. plural agreement (both of the verb and the predicate NP) in (6a) and (6b) forces two different analyses of the structures. In (6a) pine nuts and basil must be interpreted as two different items about which the same predication is made, while in (6b) they must be interpreted as one item (a dish with two things combined) about which a predication is made.

(6) a. Pine nuts and basil are my favorites.

b. Pine nuts and basil is my favorite.

In a language without this sort of agreement, the interpretation of the referent could not be constrained in this way. The hearer would be left to guess (infer) the nature of the referent(s) based on non-linguistic assumptions.

Case distinctions, such as those related to the pronouns in English, are also a way of constraining the identification of referents and their roles in the action being described, marking the NP as A/S (nominative) or non-A/S (oblique). For example, use of the nominative form of the 3sg pronoun in (7) by the speaker prevents the hearer from including any assumptions in the context of interpretation that would lead to a non-agentive interpretation of the referent of the pronoun.

(7) He left me at the train station.

In the case of Modern English, the case marking is redundant, in that grammatical relations are also marked by word order, and in fact case marking has come to be determined by word order, but this was not the case in older varieties of English, which did not use word order consistently to mark grammatical relations. What is important here is that in languages with such case marking the identification of the referent is more constrained (by the use of the marking) than in a language without such marking. For example, in Chinese there is no such case marking, and word order does not distinguish grammatical relations (see above, also LaPolla 1995, to appear), and so the hearer's identification of 
the roles of the 1sg referent and the interrogative/indefinite pronoun in (8) is unconstrained by the morphosyntactic structure.

(8) Wó shéi dōu bù rènshi. 1sg who all NEG know (a) I don't know anyone / (b) No one knows me.

The construction called "raising" in the generative literature, where an argument of an embedded clause appears in the matrix clause, is a construction which in English has an $[\mathrm{A}, \mathrm{S}]$ pivot: only the $\mathrm{A}$ or $\mathrm{S}$ of an embedded clause can be "raised" to the subject of a verb such as seem. In (9b) the A argument of the embedded clause in (9a) is "raised" to the subject of the matrix clause. This cannot happen with the $\mathrm{P}$ argument of the embedded clause, as testified by the unacceptability of $(9 \mathrm{c})$.

(9) a. It seems that man has broken the vase.

b. That man seems to have broken the vase.

c. ${ }^{*}$ The vase seems that man has broken.

This construction would have developed as speakers attempted to constrain the identification of the relevant topic by placing it in initial position. The effect of this constraint on referent identification (aside from making the $\mathrm{A}$ or $\mathrm{S}$ of the embedded clause the theme) is similar to that of the cross-clause coreference construction discussed above: the construction forces a coreference interpretation of the theme (the subject of seem) and the A or S of the embedded clause. In languages without such a constraint on "raising", such as Chinese (LaPolla 1993), where the equivalent of (9c) is possible, the interpretation of the relationship between the main topic and the embedded clause is not constrained grammatically.

In some languages there is a pivot for relativization, such that only certain arguments in a clause can be relativized on. For example, in Malagasy (Western Austronesian; Madagascar) there is an $[\mathrm{A}, \mathrm{S}]$ pivot, that is, the head of the relative clause must function as the single argument of an intransitive clause or the actor of an active voice transitive verb in the relative clause (Keenan 1976:265). In (10) there is an example of a simple clause and an example of a relative construction (Keenan 1976:265).

(10) a. Man-asa ny lamba ny zazavavy. ATV-wash DET clothes DET girl

'The girl is washing the clothes.' 
b. ny zazavavy (izay) man-asa ny lamba DET girl (that) ATV-wash DET clothes 'the girl who is washing the clothes'

In general restrictive relative clauses are used to help the hearer identify referents, but having a constraint on the head of a relative clause constrains the hearer's interpretation of the semantic role of the referent being identified. English does not have such a constraint on (finite) relativization; just about any argument can be relativized on, but the head in a Malagasy relative clause must have a specific syntactic relation within the relative clause. In (11a) we can see that simple relativization of the undergoer of the clause is not acceptable. If the head functions as the undergoer (or instrument) of the transitive verb in the relative clause, then a special voice form must be used in the relative clause, such as the passive in (11b), which can then be relativized, as in (11c) (all examples from Keenan 1976:265).

(11) a. *ny lamba (izay) man-asa ny zazavavy DET clothes (that) ATV-wash DET girl Intended: 'the clothes that the girl washed'

b. Sasa-n'ny zazavavy ny lamba. wash-PAss-DET girl DET clothes 'The clothes are washed by the girl.'

c. ny lamba (izay) sasa-n ny zazavavy DET clothes (that) wash-PASs DET girl 'the clothes that are washed by the girl'

We've seen that some languages have grammaticalized pivots for certain constructions, while others have not, and we have seen in languages that have grammaticalized pivots that we often can find the same pivot type for several constructions in the language, but which constructions have the pivot and which do not is not predictable. For example, Malagasy and Dyirbal have pivots for relativization (though the former has [A, S, derived-S(passive)] while the latter has [P, S, derived-S(antipassive)]), while English does not, even though English has an $[A, S$, derived-S(passive)] pivot for a number of other constructions. There are other languages, though, that have grammaticalized different pivot types for different constructions. One of these is Jacaltec (a morphologically ergative Mayan language of Guatemala; Van Valin 1981; using data from Craig 1977 and Datz 1980). According to Van Valin (1981:375; citing Larsen \& Norman 1979), several groups within the Mayan family have a [P, S, derived$\mathrm{S}]$ pivot for relativization, WH-question formation, and clefting, as in (12a-c) (Craig 1977:212-213). The only way an A can be relativized, questioned, or 
clefted is for it to appear in an antipassive derived-S form, as in (13a-c) (Craig 1977:213). In the antipassive, the verb is marked by the suffix $-n(i)$, and the ergative marker does not appear on the verb. ${ }^{5}$
a. $h a^{\prime}$ ix $x$ - $\varnothing-y$-'il
naj
CLEFT CL/she ASP-3ABS-3ERG-See CL/he
'It is her that he saw.' (*'It is she who saw him.')
b. mac $x-\emptyset-y$-'il naj
WH ASP-3ABS-3ERG-see CL/he
'Whom did she see?' (*`Who saw him?')
c. w-ohtaj ix $x$-Ø-y-'il naj
1sgerg-know CL/she ASP-3ABs-3ERG-see CL/he
'I know the woman that he saw.' (*'I know the woman who saw him.')
$\begin{array}{lll}\text { (13) a. ha' naj } x \text { - } \varnothing \text {-'il-ni } & \text { ix } \\ \text { CLEFT CL/he ASP-3ABs-see-ANTI CL/she }\end{array}$
'It is he that saw her.' (*'It is him that she saw.')
b. mac $x$-Ø-'il-ni
$i x$
WH ASP-3ABS-see-ANTI CL/she
'Who saw her?' (*'Whom did she see?')
c. w-ohtaj naj $x$-Ø-'il-ni ix
1sgerg-know CL/he ASP-3ABS-see-ANTI CL/she
'I know the man that saw her.' (*'I know the man that she saw.')

While there is this clear [P, S, derived-S] pivot for these constructions, there is an $[\mathrm{A}, \mathrm{S}$, derived-S] pivot for co-reference of pronouns in sequences of clauses in discourse. That is, the topical referent of a discourse will generally be $S$ or A, and if it is $\mathrm{P}$ will generally appear in a passive construction as a derived-S, as in the following two examples (Van Valin 1981:380, adapted from Datz 1980: 103, 105 - the glossing differs somewhat from the examples from Craig 1977):

(14) a. scawilal tu' xil naj hü̈e' nach'en tz'ulik; betu' x'octoj naj near that saw he $\mathrm{i}_{\mathrm{i}}$ one cave small there entered he $\mathrm{e}_{\mathrm{i}}$ yeba' sba. saylax naj yaj maẍtic'a ch'ilcha naj hide self was.looked.for he $\mathrm{e}_{\mathrm{i}}$ but never was.seen he $\mathrm{i}_{\mathrm{i}}$ 'Nearby he saw a small cave; there he entered to hide. He was looked for but he was never seen.'

b. xinitij naj yanma yulyin, stzabi naj swixie' heb brought $\mathrm{he}_{\mathrm{i}}$ his.heart in.him grasped he $\mathrm{e}_{\mathrm{i}}$ their.shoulders $\mathrm{PL}$ 
ix; x'ilaxtoj naj xol cake'; hatxca yilaxtoj naj xtxam CL was.carried he $\mathrm{e}_{\mathrm{i}}$ through air there was.carried he $\mathrm{e}_{\mathrm{i}}$ edge con̈ob town 'Gathering his courage, he grasped the women's shoulders, and he was carried through the air, and there he was carried to the edge of town.'

In these examples the pronouns referring to the topical referent and the passivized verbs are italicized. The verbs are passivized because of the preference for the pronoun referring to the topical animate referent to be in A or S (including derived-S) function. So in this language we have the grammaticalization of pivots, but more than one type within the same language.

\section{Conclusion}

We have seen that languages differ in terms of what constraints on referent identification they have conventionalized. There may be differences in how strong the constraints are as well; since they are conventionalized, and conventionalization is a gradual process, even when two languages both conventionalize a particular type of constraint, the constraints may hold to different degrees in different languages. Grammatical relations are then a constructionspecific, and therefore language-specific phenomenon, not a cross-linguistic category (see also Van Valin 1977, 1981; Van Valin \& LaPolla 1997: Ch. 6; Dryer 1997; LaPolla to appear). Given this fact, and the fact that the function of constraining the interpretation of referents is not unique to the types of pivots associated with grammatical relations, the logical conclusion is that there is no category of "subject" to talk about. Use of this term in language descriptions is problematic, particularly when it is not defined properly for the language being described, as the reader does not know which particular constraints have been conventionalized in the language. Even closely related languages long talked about as having a category of "subject", such as Italian and English, differ in terms of which constraints on referent identification have been conventionalized. For example, Italian has not conventionalized a strong cross-clause coreference constraint in conjoined clauses the way English has (ex. (3)). Very few linguists are aware of this difference because of the assumption of "subject" as a category, and the assumption that subject is comparable across languages.

The nature of being a language-specific phenomenon is in fact not specific to the constructions traditionally associated with grammatical relations. I 
would argue that we should treat all morphosyntactic phenomena as languagespecific phenomena. In analyzing a language, then, we cannot take any categories or constructions as "given"; we need to look at what constructions and marking have become conventionalized in the language, and then look at each construction or marking found to see what functional domain it is constraining the interpretation of, how and to what degree it constrains the interpretation of that domain, and with what morphosyntactic form(s) it constrains the interpretation of the domain.

\section{Notes}

* Although I was not a student of Prof. Shibatani, I have been learning from him since my student days through his many writings. I have also since been fortunate to have gotten to know Prof. Shibatani personally, and have benefited greatly from our discussions. I would like to offer this paper to Prof. Shibatani as an expression of my respect, gratitude, and affection.

1. Prof. Shibatani has recently (2002) argued that passive, inverse, and split-ergativity all are manifestations of voice, as all 'refer to the origin and terminal point of an action' (2002:16), where natural event configurations (e.g. speech act participant acts on 3rd person) receive the unmarked voice expression and unnatural event configurations (e.g. 3rd person acting on speech act participant) receive the marked voice expression. In the terms of this paper I would say that they all constrain the identification of the roles of the referents involved.

2. It is a neutralization because either A or S can be the pivot, but it is restricted because the P (patient) argument of a transitive cannot appear as pivot. See Van Valin and LaPolla (1997: Ch. 6) for a full discussion of pivots and their use in cross-clause referent tracking. Here I am using the term pivot in a somewhat broader sense, to include both pivot and controller, and am talking about referent identification in a more general sense than just cross-clause referent tracking in discourse.

3. Abbreviations used in the examples: ABS absolutive; AGT agentive; ANTI antipassive marker; ASP aspect marker; ATV active voice; CL classifier; DET determiner; DEM demonstrative pronoun; ERG ergative; Intrans.PAST third person intransitive past; LOC locative/dative; PASs passive voice; PL plural; INST instrumental voice; PFV perfective; PS predicate sequence; $\mathrm{R} / \mathrm{M}$ reflexive/middle; TMdys past tense, 1 day-1 year ago; Trans.PAsT 3rd person transitive past; wH wh-question marker.

4. Grammaticalization and lexicalization are both forms of conventionalization, and differ only in the generality of the elements produced.

5. Due to the effect of certain morphophonemic rules, the verbs in $(12 \mathrm{a}-\mathrm{c})$ would be pronounced [xil]. See Craig (1977:213-214). 


\section{References}

Comrie, B. (1988). "Coreference and conjunction reduction in grammar and discourse". In J. Hawkins (Ed.), Explaining Language Universals (pp. 186-208). Oxford: Basil Blackwell. Craig, C. G. (1977). The Structure of Jacaltec. Austin and London: University of Texas Press.

Datz, M. (1980). Jacaltec Syntactic Structures and the Demands of Discourse. PhD dissertation, University of Colorado.

Dixon, R. M. W. (1972). The Dyirbal Language of North Queensland. Cambridge: Cambridge University Press.

Dixon, R. M. W. (1980). The Languages of Australia. Cambridge, London, and New York: Cambridge University Press.

Dryer, M. S. (1997). "Are grammatical relations universal?" In J. Bybee, J. Haiman, \& S. A. Thompson (Eds.), Essays on Language Function and Language Type (pp. 115-143). Amsterdam and Philadelphia: John Benjamins.

Grice, H. P. (1975). "Logic and conversation”. In P. Cole \& J. L. Morgan (Eds.), Speech Acts (pp. 41-58). New York: Academic Press.

Keenan, E. L. (1976). Remarkable subjects in Malagasy. In C. N. Li (Ed.), Subject and Topic (pp. 247-301). New York: Academic Press.

LaPolla, R. J. (1993). "Arguments against 'subject' and 'direct object' as viable concepts in Chinese". Bulletin of the Institute of History and Philology, 63, 759-813.

LaPolla, R. J. (1995). “Pragmatic relations and word order in Chinese." In P. Downing \& M. Noonan (Eds.), Word Order in Discourse (pp. 297-329). Amsterdam and Philadelphia: John Benjamins.

LaPolla, R. J. (to appear). "On describing word order". In F. Ameka, A. Dench, \& N. Evans (Eds.), Catching Grammar. Berlin: Mouton de Gruyter. (downloadable from http://www.latrobe.edu.au/linguistics/stlapolla_data/PublicationItems/Papers/ describingwo.pdf)

LaPolla, R. J. (2003). "Why languages differ: Variation in the conventionalization of constraints on inference." In D. Bradley, R. J. LaPolla, B. Michailovsky, \& G. Thurgood (Eds.), Language Variation: Papers on Variation and Change in the Sinosphere and in the Indosphere in Honour of James A. Matisoff (pp. 113-144). Canberra: Pacific Linguistics, Australian National University.

Larsen, T. \& Norman, W. (1979). "Correlates of ergativity in Mayan grammar”. In F. Plank (Ed.), Ergativity: Towards a Theory of Grammatical Relations (pp. 348-370). London: Academic Press.

Reddy, M. J. (1979). "The conduit metaphor - a case of frame conflict in our language about language". In A. Ortony (Ed.), Metaphor and Thought (pp. 284-324). Cambridge: Cambridge University Press.

Shibatani, M. (1991). “Grammaticization of topic into subject”. In E. C. Traugott \& B. Heine (Eds.), Approaches to Grammaticalization, Vol. II (pp. 93-133). Amsterdam and Philadelphia: John Benjamins.

Shibatani, M. (2002). "On the conceptual framework for voice phenomena”. Paper presented at City University of Hong Kong, May 8, 2002.

Sperber, D. \& Wilson, D. (1986/1996). Relevance: Communication and Cognition (2nd edition, 1996). Cambridge, MA: Harvard University Press. 
Van Valin, R. D., Jr. (1977). "Ergativity and the universality of subjects". In W. A. Beach, S. E. Fox, \& S. Philosoph (Eds.), Papers from the Thirteenth Regional Meeting[:] Chicago Linguistics Society (pp. 689-705). Chicago: Chicago Linguistics Society.

Van Valin, R. D., Jr. (1981). "Grammatical relations in ergative languages". Studies in Language, 5, 361-394.

Van Valin, R. D., Jr. \& LaPolla, R. J. (1997). Syntax: Structure, Meaning, and Function. Cambridge: Cambridge University Press. 